Session \#2139

\title{
TENT CASH FLOW DESIGNS AND ANALYSIS FOR GRADIENT CASH FLOW LECTURES
}

\author{
Adedeji B. Badiru, H. Olufemi Omitaomu \\ Department of Industrial Engineering \\ University of Tennessee, Knoxville, TN 37996-0700
}

\begin{abstract}
Students learn better if fun and motivational aids are incorporated into instructional materials. This paper presents an innovative method of introducing students to the design and analysis of arithmetic gradient series cash flows in engineering economy courses. Engineering economy students are typically intimidated by arithmetic gradient series cash flows. Hence, it is beneficial to develop creative ways to make the material interesting and less formidable. Several profiles of arithmetic gradient series cash flows are presented along with techniques of deriving closed form equations for their net present values. The designs are based on classroom lecture notes of the authors and have been used extensively over several years to motivate students and ease their fear of the analysis of arithmetic gradient series cash flows. The pedagogical benefits derived from the tent models help students to have a better understanding of other cash flow profiles. The models are given interesting names such as "The Executive Tent," "Saw-Tooth Tent," "Cathedral tent," and so on. MATLAB software modules were developed for a computer implementation of the general present value equation of the Basic Tent cash flow.
\end{abstract}

\section{Introduction}

Learning experiences should not only be challenging, but also fun. In the teaching of engineering economy, instructors continue to strive to develop new and interesting ways to present new concepts. Analysis of arithmetic gradient series cash flows is one of the most dreaded problems by many engineering economy students. In the attempt to put students at ease, the authors have developed an interesting graphical representation of arithmetic gradient series cash flows. The approach presents arithmetic gradient series cash flows in familiar shapes of tents ${ }^{2}$. The cash flows are fun to design and analyze.

Cash flow diagrams are, in general, used in the teaching and practice of engineering economic analysis to evaluate present and future worth receipts and disbursements of investment alternatives. Periodic receipts and payments usually occur in five different series: uniform (or equal) amount series, single present or future receipt, arithmetic gradient series, geometric series, and irregular series ${ }^{7}$. However, arithmetic gradient series has many applications in real life 
investment and more emphasis is usually placed on its understanding when teaching engineering economy. However, the analysis of this type of cash flow profile usually intimidates students. The understanding and analysis of cash flow diagrams is an integral part of engineering economy education especially at the undergraduate level. Several innovative methods of enhancing the teaching of engineering economy are in the literature, including incorporating spreadsheets into the classroom lectures 1,5 , the need for curriculum enhancement by integrating research advances into course materials ${ }^{4,6}$, and practical factors that increase the efficacy of teaching engineering economy $^{8}$. In this paper, several designs and a close-form analysis of some real-life arithmetic gradient series cash flow profiles are presented to help students have a better understanding of this and other cash flow profiles and their analysis. The pedagogical benefits derived from the tent models help students to have a better understanding of other cash flow profiles. The models are given interesting names such as "The Executive Tent," "Saw-Tooth Tent," "Cathedral tent," and so on. MATLAB software modules were developed for a computer implementation of the general present value equation of the Basic Tent cash flow.

\section{Background of the Analysis}

Several real life personal and corporate financial dealings are beyond the single sums and the uniform series cash flow models; they tend more towards the arithmetic gradient series and the geometric gradient series models. The arithmetic gradient series cash flow involves an increase or decrease of a constant amount in the cash flow of each analysis period. Thus, the receipt or disbursement at a particular time is greater or lower than the receipt or disbursement at the preceding period by a constant amount. This constant amount is denoted by G, for "Gradient" amount. The total present worth of the arithmetic gradient series is calculated by using the present amount factor to convert each individual amount from time $t$ to time 0 at an interest rate of $i \%$ per period and taking the summation to obtain the present worth. The finite summation results in a closed form expression for the particular cash flow profile under consideration.

\section{Real-life Applications of Arithmetic Gradient Series}

Arithmetic gradient series cash flows feature prominently in many contract payments. Good examples can be found in the contracts of sports professionals. The pervasiveness and high publicity of such contracts make the analysis of arithmetic gradient series quite appealing and economically necessary. A case study, which the first author frequently cites in his lectures, is the 1984 highly publicized contract of Steve Young, a quarterback for the LA Express in the former USFL (United States Football League). The contract was widely reported as being worth $\$ 40$ million dollars at that time. The cash flow profile of the contract revealed an intricate use of various segments of arithmetic gradient series cash flows. In fact, a sports reporter ${ }^{3}$ commented that "the most amazing part of this whole deal is how little, relatively speaking, the Express is paying to get both Young and an enormous amount of publicity." He concluded that an athlete "needs not only an agent to watch what the club is doing, but also an attorney to watch what the agent is doing" with the contract cash flow profiles. We might add that an economic analyst is also needed to verify the cash flow claims of agents and attorneys. Finding Young's contract curious, Badiru assigned it as a case study for computational analysis of the present value. It was 
found that, contrary to the $\$ 40$ million touted in the press, the present worth of the contract was only about $\$ 5$ million at that time. The trick is that the club included some deferred payments stretching over 37 years (1990-2027) at a 1984 present cost of only \$2.9 million. The deferred payments were reported as being worth $\$ 34$ million, which was the raw sum of the amounts in the deferred cash flow profile. It turns out that clever manipulations of an arithmetic gradient series cash flow can create unfounded perceptions of the worth of a professional sports contract. This explains why some sports professionals suddenly find themselves bankrupt shortly after receiving what they assume to be multi-million dollar contracts. Similar examples were found in reviewing the contracts of other sports professionals. Other examples: Barry Sanders' deal with the Detroit Lions in the mid 1990s was reportedly worth \$34 million. The contract negotiation went on for several months because there was a sticking point regarding the "structuring" of the payments. Likewise, the Brian Bosworth contract with the Seattle Seahawks in 1987 made a clever use of the structuring of the arithmetic gradient series. So, the use of the arithmetic gradient series is more common in real life than what one might suspect. Consequently, engineering economy students need to be taught to overcome the fear of the arithmetic gradient series. In pedagogical terms, the teaching of the topic should be made more interesting and less threatening. The tent cash flow concept has been found to be one suitable approach as discussed in a later section on outcome assessment.

\section{Design and Analysis of Tent Cash Flow Profiles}

Real-life arithmetic gradient series cash flows usually start with some base amount at the end of the first period and then increase or decrease by a constant amount thereafter. The nonzero base amount is denoted as $\mathrm{A}_{\mathrm{T}}$ starting at period $\mathrm{T}$. The analysis of the present worth for such cash flows requires breaking the cash flow into a uniform series cash flow of amount $\mathrm{A}_{\mathrm{T}}$ starting at period $\mathrm{T}$ and an arithmetic gradient series cash flow with a zero base amount. The uniform series present worth formula is used to calculate the present worth of the uniform series portion while the basic arithmetic gradient series formula is used to calculate the arithmetic gradient series part of the cash flow profile. The overall present worth is then calculated as:

$$
P=P_{\text {uniform series }} \pm P_{\text {arithmetic gradient series }}
$$

Figure 1 presents a conventional arithmetic gradient series (GS) cash flow. Each cash flow amount at time $t$ is defined as $A_{t}=(t-1) G$. The standard formula for this basic arithmetic gradient series profile is derived as:

$$
\begin{aligned}
P & =\sum_{t=1}^{n} A_{t}(1+i)^{-t} \\
& =\sum_{t=1}^{n}(t-1) G(1+i)^{-t} \\
& =G \sum_{t=1}^{n}(t-1)(1+i)^{-t}
\end{aligned}
$$


$=$

$=G\left[\frac{(1+i)^{n}-(1+n i)}{i^{2}(1+i)^{n}}\right]$

$=\mathrm{G}(\mathrm{P} / \mathrm{G}, \mathrm{i}, \mathrm{n})$, in tabulated form.

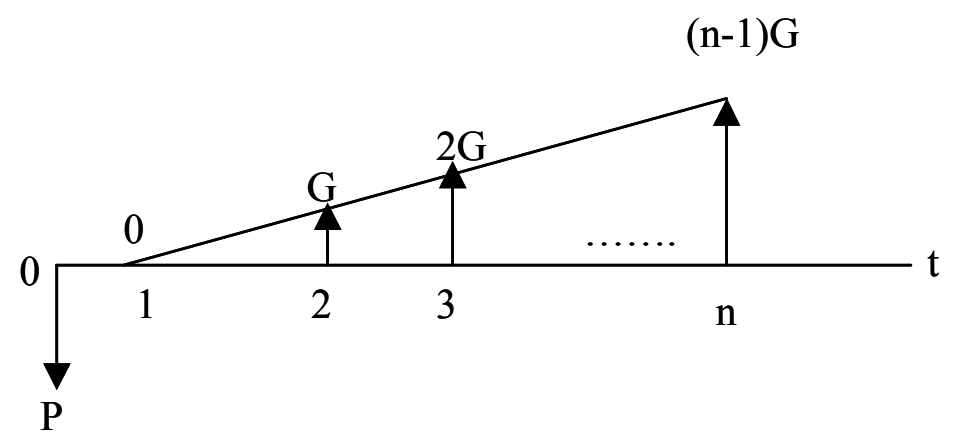

Figure 1: Conventional Arithmetic Gradient Series (AGS) Cash Flow

The computational process of deriving and using the $P / G$ formula is where new engineering economy students often stumble. Recognizing the tent-like structure of the cash flow, Badiru ${ }^{2}$ originated the idea of tent cash flows. These were originally known as Badiru's tents, and they featured as the last problem on every engineering economy test that he gave from 1988 through 1996 at the University of Oklahoma. Because of the appeal of technique, it was formulized into a regular instructional aid.

Figure 2 presents the Basic Tent (BT) cash flow profile. It is composed of an up-slope gradient and a down-slope portion, both on a uniform series base of $A_{1}$.

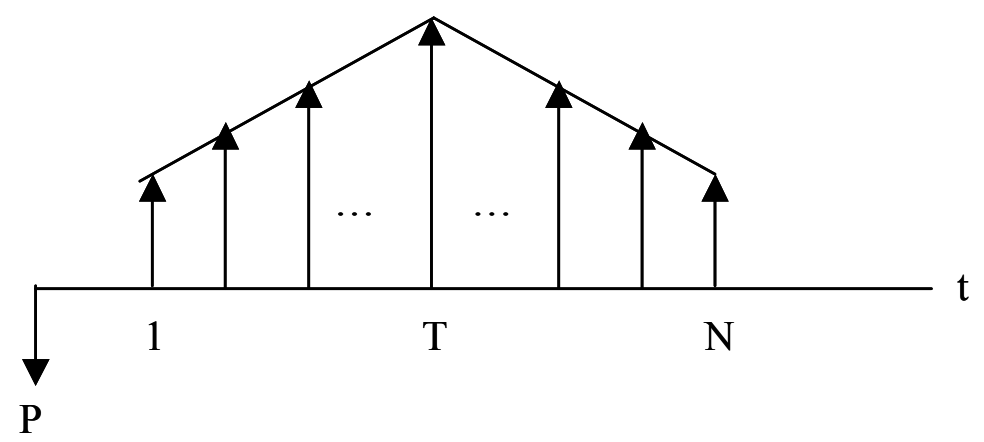

Figure 2: Basic Tent (BT) cash flow profile

Computational Formula Analysis of BT Cash Flow is shown below: 
For the first half of the cash flow (from $t=1$ to $t=T$ )

$$
\begin{aligned}
& P_{a}=\sum_{t=1}^{T} A_{1}(1+i)^{-t}+\sum_{t=1}^{T} A_{t}(1+i)^{-t} \\
& \quad \text { where } A_{t}=(t-1) G \\
& P_{a}=\sum_{t=1}^{T} A_{1}(1+i)^{-t}+G \sum_{t=1}^{T}(t-1)(1+i)^{-t} \\
& P_{a}=A_{1}\left[\frac{(1+i)^{T}-1}{i(1+i)^{T}}\right]+G\left[\frac{(1+i)^{T}-(1+T i)}{i^{2}(1+i)^{T}}\right]
\end{aligned}
$$

For the second half of the cash flow (from $t=T+1$ to $t=N$ )

$$
\begin{aligned}
& P_{b}=\sum_{t=T+1}^{N} A_{T+1}(1+i)^{-t}-\sum_{t=T+1}^{N} A_{t}(1+i)^{-t} \\
& \text { where } A_{t}=(t-1) G \\
& P_{b}=A_{T+1} \sum_{t=T+1}^{N}(1+i)^{-t}-\sum_{t=T+1}^{N}(t-1) G(1+i)^{-t} \\
& \text { : } \\
& P_{b}=A_{T+1}\left[\frac{(1+i)^{N-T}-1}{i(1+i)^{N-T}}\right]-G\left[\frac{(1+i)^{N-T}-[1+(N-T) i]}{i^{2}(1+i)^{N-T}}\right] \\
& \text { let } x=(N-T) \\
& \therefore P_{b}=A_{T+1}\left[\frac{(1+i)^{x}-1}{i(1+i)^{x}}\right]-G\left[\frac{(1+i)^{x}-(1+x i)}{i^{2}(1+i)^{x}}\right]
\end{aligned}
$$

Hence, $\quad P=P_{a}+P_{b}(1+i)^{-T}$

The basic approach to solving this type of cash flow profile is to partition it into simpler forms. By partitioning, BT can be solved directly using standard cash flow conversion factors. That is, the solution can be obtained as the sum of a uniform series cash flow (Base Amount), an increasing arithmetic gradient series, and a decreasing arithmetic gradient series. That is,

$$
P=G(P / A, i, N)+G(P / G, i, T)+[G(T-2)(P / A, i, N-T)-G(P / G, i, N-T)](P / F, i, T)
$$

The above two approaches should yield the same result. Obviously, the partitioning approach using existing standard factors is a more ingenious method. One common student error when using the existing arithmetic gradient series factor is the use of incorrect number of periods, $n$. It should be recognized that the standard arithmetic gradient series factor was derived for a situation where $\mathrm{P}$ is located one period before the "nose" of the increasing series. Students often tend to locate P right at the same point on the time line as the "nose" of the series, which means that $n$ will be off by one unit. One way to avoid this error is to redraw the time line and 
renumber it from a reference point of zero. That is, relocate time zero $(t=0)$ to one period before the arithmetic gradient series begins.

Figure 3 shows a profile of the Executive Tent (ET) cash flow profile. It has a constant amount of increasing and decreasing arithmetic gradient series. The magnitudes of the cash flow amounts at times $T_{j}(j=1,2, \ldots)$ are equal.

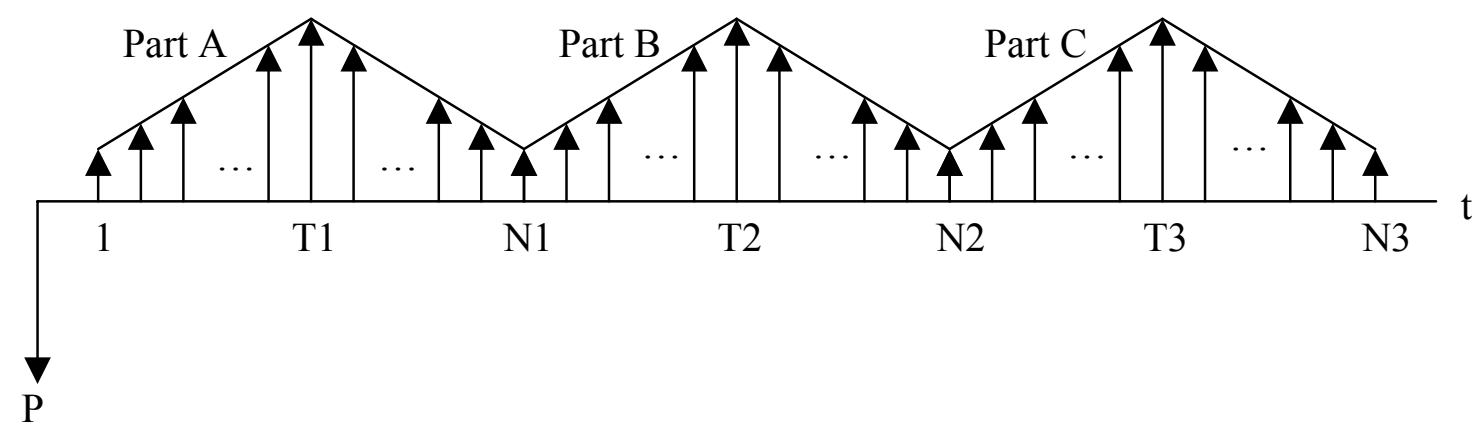

Figure 3: Executive Tent (ET) cash flow profile

For Part A:

$P_{A}=P_{1}+P_{T_{1}+1}(1+i)^{-T_{1}}$

where:

$P_{1}=A_{1}\left[\frac{(1+i)^{T_{1}}-1}{i(1+i)^{T_{1}}}\right]+G\left[\frac{(1+i)^{T_{1}}-\left(1+T_{1} i\right)}{i^{2}(1+i)^{T_{1}}}\right]$

and

$P_{T_{1}+1}=A_{T_{1}+1}\left[\frac{(1+i)^{x_{1}}-1}{i(1+i)^{x_{1}}}\right]-G\left[\frac{(1+i)^{x_{1}}-\left(1+x_{1} i\right)}{i^{2}(1+i)^{x_{1}}}\right]$

while $x_{1}=\left(N_{1}-T_{1}\right)$

For Part $B$ :

$P_{B}=P_{N_{1}+1}(1+i)^{-N_{1}}+P_{T_{2+1}}(1+i)^{-T_{2}}$

where:

$P_{N_{1}+1}=A_{N_{1}+1}\left[\frac{(1+i)^{T_{2}}-1}{i(1+i)^{T_{2}}}\right]+G\left[\frac{(1+i)^{T_{2}}-\left(1+T_{2} i\right)}{i^{2}(1+i)^{T_{2}}}\right]$

and

$P_{T_{2+1}}=A_{T_{2}+1}\left[\frac{(1+i)^{x_{2}}-1}{i(1+i)^{x_{2}}}\right]-G\left[\frac{(1+i)^{x_{2}}-\left(1+x_{2} i\right)}{i^{2}(1+i)^{x_{2}}}\right]$

while $x_{2}=\left(N_{2}-T_{2}\right)$ 
For Part C:

$P_{C}=P_{N_{2}+1}(1+i)^{-N_{2}}+P_{T_{3+1}}(1+i)^{-T_{3}}$

where:

$P_{N_{2}+1}=A_{N_{2}+1}\left[\frac{(1+i)^{T_{3}}-1}{i(1+i)^{T_{3}}}\right]+G\left[\frac{(1+i)^{T_{3}}-\left(1+T_{3} i\right)}{i^{2}(1+i)^{T_{3}}}\right]$

and

$P_{T_{3+1}}=A_{T_{3}+1}\left[\frac{(1+i)^{x_{3}}-1}{i(1+i)^{x_{3}}}\right]-G\left[\frac{(1+i)^{x_{3}}-\left(1+x_{3} i\right)}{i^{2}(1+i)^{x_{3}}}\right]$

while $x_{3}=\left(N_{3}-T_{3}\right)$

$\therefore P=P_{A}+P_{B}+P_{C}$

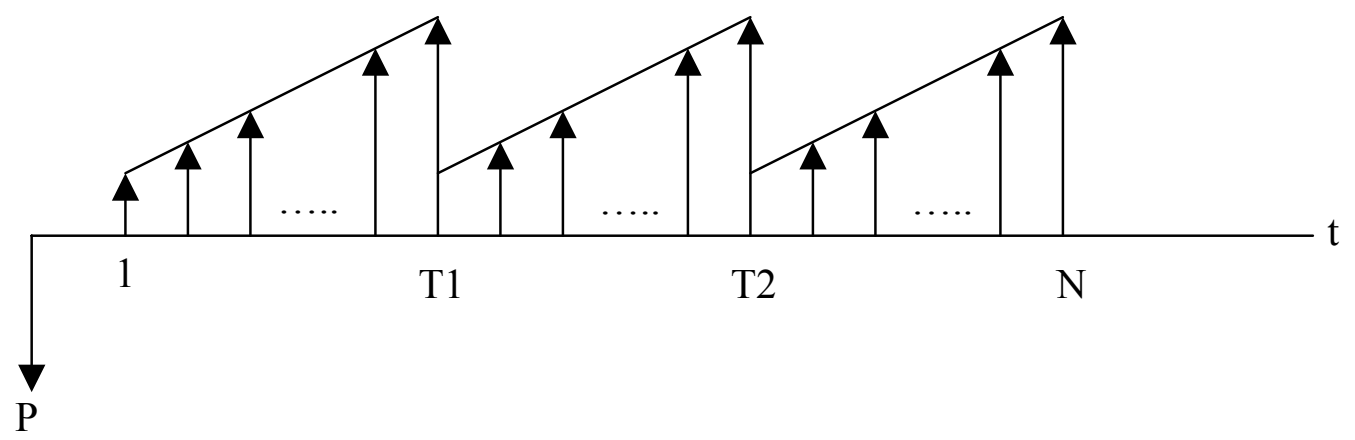

Figure 4: Saw-Tooth Tent (STT) cash flow profile

Figure 4 presents a Saw-Tooth Tent (STT) cash flow profile. The present value analysis of the cash flow is computed as presented below.

$P=P_{1}+P_{T_{1}+1}(1+i)^{-T_{1}}+P_{T_{2}+1}(1+i)^{-T_{2}}$

where:

$P_{1}=A_{1}\left[\frac{(1+i)^{T_{1}}-1}{i(1+i)^{T_{1}}}\right]+G\left[\frac{(1+i)^{T_{1}}-\left(1+T_{1} i\right)}{i^{2}(1+i)^{T_{1}}}\right]$

$P_{T_{1}+1}=A_{T_{1}+1}\left[\frac{(1+i)^{T_{2}}-1}{i(1+i)^{T_{2}}}\right]+G\left[\frac{(1+i)^{T_{2}}-\left(1+T_{2} i\right)}{i^{2}(1+i)^{T_{2}}}\right]$

$P_{T_{2}+1}=A_{T_{2}+1}\left[\frac{(1+i)^{N}-1}{i(1+i)^{N}}\right]+G\left[\frac{(1+i)^{N}-(1+N i)}{i^{2}(1+i)^{N}}\right]$ 


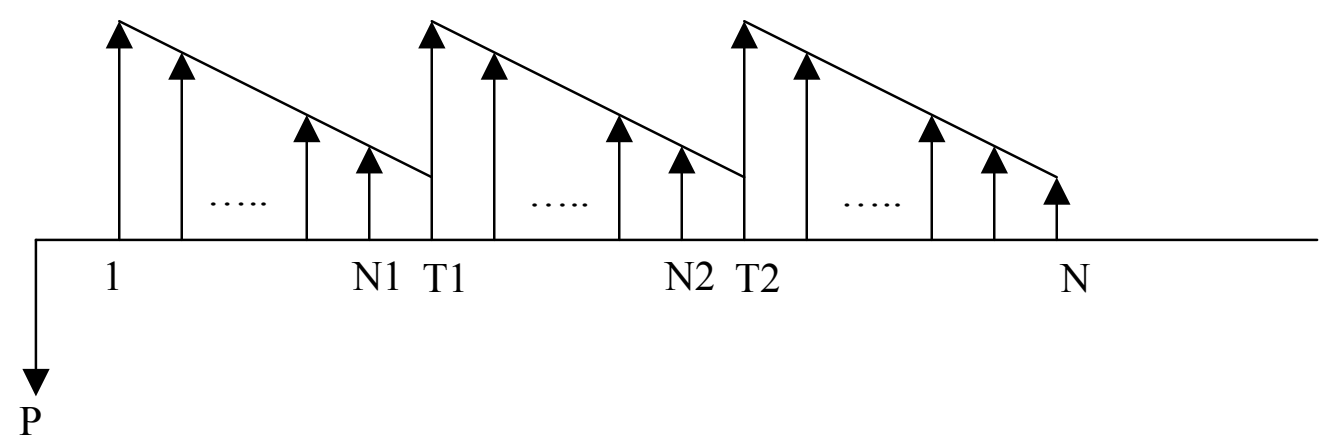

Figure 5: Reversed Saw-Tooth Tent (R-STT) cash flow profile

In Figure 5, a Reversed Saw-Tooth Tent is constructed. Its present value computation is handled as shown below.

$P=P_{1}+P_{T_{1}}(1+i)^{-T_{1}}+P_{T_{2}}(1+i)^{-T_{2}}$

where:

$P_{1}=A_{1}\left[\frac{(1+i)^{N_{1}}-1}{i(1+i)^{N_{1}}}\right]-G\left[\frac{(1+i)^{N_{1}}-\left(1+N_{1} i\right)}{i^{2}(1+i)^{N_{1}}}\right]$

$P_{T_{1}}=A_{T_{1}}\left[\frac{(1+i)^{x_{1}}-1}{i(1+i)^{x_{1}}}\right]-G\left[\frac{(1+i)^{x_{1}}-\left(1+x_{1} i\right)}{i^{2}(1+i)^{x_{1}}}\right]$

while $x_{1}=\left(N_{2}-N_{1}\right)$

$P_{T_{2}}=A_{T_{2}}\left[\frac{(1+i)^{x_{2}}-1}{i(1+i)^{x_{2}}}\right]-G\left[\frac{(1+i)^{x_{2}}-\left(1+x_{2} i\right)}{i^{2}(1+i)^{x_{2}}}\right]$

while $x_{2}=\left(N-N_{2}\right)$

Increasingly complicated profiles can be designed depending on the level of complexity desired to test different levels of student understanding. Note that the ET, STT, and R-STT cash flows can also be solved by the partitioning approach shown earlier for the BT cash flow.

\section{Derivation of General Tent Equation}

To facilitate a less convoluted use of the tent cash flow computations, we have derived a general tent cash flow equation. This is suitable for adoption by engineering economy instructors or students. We combine all the tent cash flow equations into a general tent cash flow equation that is amenable to software implementation. A MATLAB implementation is shown later in the section. The general equation is as follows: 
$P_{0}=A_{0}+A_{1}\left[\frac{(1+i)^{T}-1}{i(1+i)^{T}}\right]+G_{1}\left[\frac{(1+i)^{T}-(1+T i)}{i^{2}(1+i)^{T}}\right]$

$P_{T}=A_{T 1}\left[\frac{(1+i)^{x}-1}{i(1+i)^{x}}\right]+G_{2}\left[\frac{(1+i)^{x}-(1+x i)}{i^{2}(1+i)^{x}}\right]$

when $G_{1} \geq 0$ or $G_{2} \leq 0$,

$T P V_{0}=P_{0}+P_{T}(1+i)^{-T}$

when $G_{1}<0$ or $G_{2}>0$,

$T P V_{0}=P_{0}-P_{T}(1+i)^{-T}$

where

$T P V_{0}=$ Total Present Value at time $\mathrm{t}=0$

$P_{0}=$ Present Value for the first half of the tent at time $\mathrm{t}=0$

$P_{T}=$ Present Value for the second half of the tent at time $\mathrm{t}=\mathrm{T}$

$i=$ interest rate in fraction

$N=$ number of periods

$T=$ the center time value of the tent

$x=(N-T)$

$A_{0}=$ amount at time $\mathrm{t}=0$

$A_{1}=$ amount at time $\mathrm{t}=1$

$A_{T 1}=$ amount at time $\mathrm{t}=\mathrm{T}+1$

$G_{1}=$ gradient series of the first half of the tent

$\Rightarrow$ increasing $G_{1}$ (up-slope) is a positive value

and decreasing $G_{1}$ (down-slope) is a negative value

$G_{2}=$ gradient series of the second half of the tent

$\Rightarrow$ increasing $G_{2}$ (up-slope) is a positive value

and decreasing $G_{2}$ (down-slope) is a negative value

This general tent cash flow equation can be used for either one-sided (see Figure 1) or two-sided (see Figure 2) tents. It can also be used for Executive Tents with more than two sides. The process involved in this case is to divide the tent into smaller sections of two sides; such as Part A, Part B, and Part C (see Figure 3) and then use the equation to solve for the present value of each part at time $\mathrm{t}=0, \mathrm{t}=\mathrm{N} 1$, and $\mathrm{t}=\mathrm{N} 2$. The present value of the future values at $\mathrm{t}=\mathrm{N} 1$ and $\mathrm{t}=\mathrm{N} 2$ 
are added to the present value at $\mathrm{t}=0$ to determine the overall present value of the Executive Tent at $\mathrm{t}=0$. This general tent equation eliminates the problem associated with incorrect number of periods and makes geometric series analysis interesting. This equation can also be used for situations where the uniform series base of $A_{1}$ is zero by finding the present value at time $\mathrm{t}=1$ and taking it back one step to determine the total present value at time $\mathrm{t}=0$. Other scenarios can also be considered by appropriate manipulations of the equation.

\section{Illustrative Software Examples}

A MATLAB module was developed for this equation and used to solve selected examples of tent cash flow problems.

\section{EXAMPLE I}

Professor Badiru's security tent has a portion under ground and a portion above ground as represented by the cash flow in Figure 6. Using arithmetic gradient series factor as appropriate, find the present value, $\mathrm{PV}, \quad($ at $\mathrm{t}=0$ ) of the tent cash flow if the interest rate per period is $10 \%$.

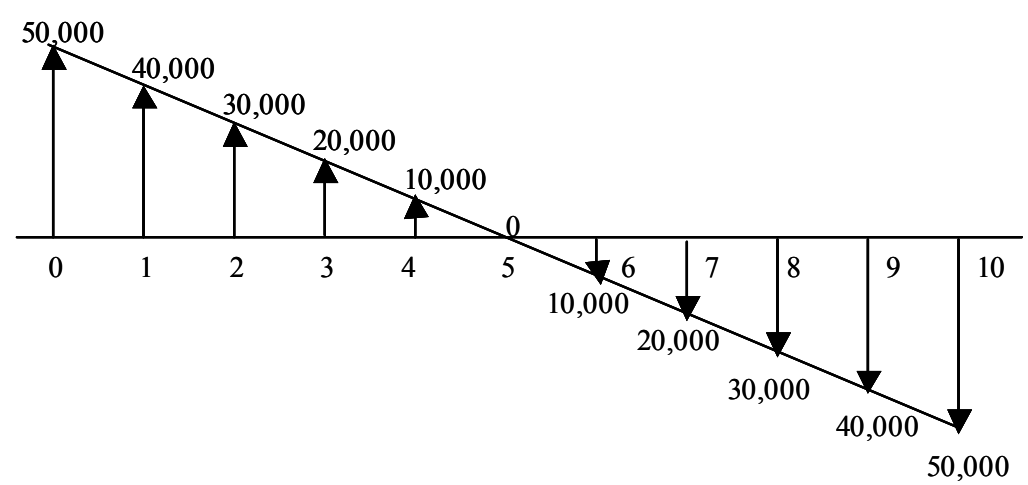

Figure 6: Professor Badiru's Security Tent Cash Flows Computation

The MATLAB diary for the implementation of the module for the above tent is as follows:

tent(int,A0,A1,AT1,G1,G2,T,N); i.e.

tent $(10,50000,40000,10000,-10000,10000,5,10)$;

This Cash Flow has the following data:

The Interest Rate in percent (int): $\quad 10$

The Amount at Time $\mathrm{t}=0(\mathrm{~A} 0)$ : $\quad \$ 50000$

The Amount at Time $\mathrm{t}=1(\mathrm{~A} 1)$ : $\quad \$ 40000$

The Amount at Time $\mathrm{t}=\mathrm{T}+1(\mathrm{AT} 1)$ : $\quad \$ 10000$

The $G$ value for the first half of the tent $(\mathrm{G} 1)$ : $\quad \$-10000$ 
The $\mathrm{G}$ value for the second half of the tent $(\mathrm{G} 2)$ : $\$ 10000$

The Center of the Tent at Time $\mathrm{t}=\mathrm{T}(\mathrm{T})$ : $\quad 5$

The Total Number of Periods $(\mathrm{N})$ : $\quad 10$

The Tent Cash Flow Analysis shows that:

The Present Value of the First Half of the Tent at time $t=0$ is $\$ 133013$

The Present Value of the Second Half of the Tent at time $\mathrm{t}=\mathrm{T}$ is $\$ 106526$

The Total Present Value (TPV) of the Tent at time $t=0$ is $\$ 66869.30$

We can also partition the cash flow into a uniform series of $\$ 50,000$ from $t=0$ to $t=10$ minus an arithmetic gradient series starting at $\mathrm{t}=0$. Then, the solution becomes

$$
\begin{aligned}
P & =[50,000(P / A, 10 \%, 11)-10,000(P / G, 10 \%, 11)](F / P, 10 \%, 1) \\
& =[324,750-263,960](1.1) \\
& =\$ 66,869.00
\end{aligned}
$$

A brute-force solution approach yields:

$$
\begin{aligned}
\mathrm{PV} & =\sum_{t=0}^{10} A_{t}(P / F, i \%, t) \\
& =\$ 10,000\left[\begin{array}{l}
5+4(1.1)^{-1}+3(1.1)^{-2}+2(1.1)^{-3}+1(1.1)^{-4}+0(1.1)^{-5} \\
-1(1.1)^{-6}-2(1.1)^{-7}-3(1.1)^{-8}-4(1.1)^{-9}-5(1.1)^{-10}
\end{array}\right] \\
& =\$ 10,000[13.3012-6.6143] \\
& =\$ 66,869.00
\end{aligned}
$$

Using the standard arithmetic gradient series, as required by the problem yields:

$\mathrm{PV}=P_{a}-P_{b}$

where

$$
\begin{aligned}
P_{a} & =[50,000+40,000(P / A, 10 \%, 5)-10,000(P / G, 10 \%, 5)] \\
& =\$ 133,020.00
\end{aligned}
$$

$$
\begin{aligned}
P_{b} & =[10,000(P / G, 10 \%, 6)](P / F, 10 \%, 4) \\
& =\$ 66,141.72
\end{aligned}
$$

$\therefore P V=\$ 133,020.00-\$ 66,141.72$

$=\$ 66,878.28 \approx \$ 66,869.00$ within the limits of the round-off errors produced by the Table entries. 


\section{EXAMPLE II}

In Figure 7, we can use the general tent cash flow equation to find the present value of this multiple Basic Tents at time $\mathrm{t}=0$ where $\mathrm{i}=10 \%$ per period.

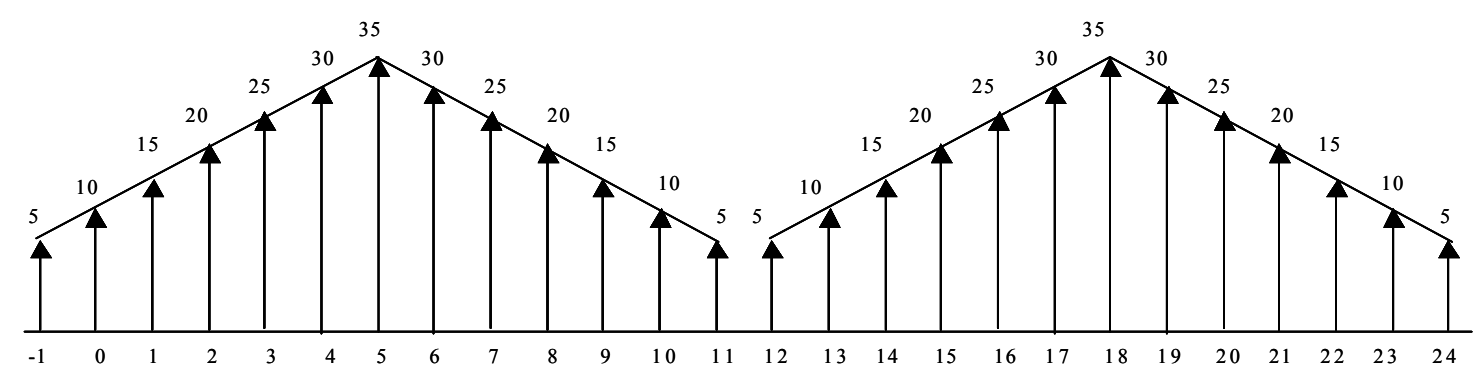

Figure 7: Dual Basic Tent Cash Flows Computation

Since this tent consists of two parts, we should use the general equation to determine the present value at time $\mathrm{t}=0$ for the first part and the present value at time $\mathrm{t}=11$ for the second part.

For the First Basic Tent, the result of the MATLAB module is:

tent(int,A0,A1,AT1,G1,G2,T,N); i.e.

$\operatorname{tent}(10,10,15,30,5,-5,5,11)$

This Cash Flow has the following data:

\begin{tabular}{|c|c|}
\hline The Interest Rate in percent (int): & 10 \\
\hline The Amount at Time $\mathrm{t}=0$ (A0): & $\$ 10$ \\
\hline The Amount at Time $\mathrm{t}=1$ (A1): & $\$ 15$ \\
\hline The Amount at Time $\mathrm{t}=\mathrm{T}+1$ (AT1): & $\$ 30$ \\
\hline The $G$ value for the first half of the tent $(\mathrm{G} 1)$ : & $\$ 5$ \\
\hline The $G$ value for the second half of the tent (G2): & : \$-5 \\
\hline The Center of the Tent at Time $\mathrm{t}=\mathrm{T}(\mathrm{T})$ : & 5 \\
\hline The Total Number of Periods $(\mathrm{N})$ : & 11 \\
\hline
\end{tabular}

The Tent Cash Flow Analysis shows that:

The Present Value of the First Half of the Tent at time $t=0$ is $\$ 101.171$

The Present Value of the Second Half of the Tent at time $\mathrm{t}=\mathrm{T}$ is $\$ 82.237$

The Total Present Value (TPV) of the Tent at time $t=0$ is $\$ 152.23$ 
To solve the Second Basic Tent, we renumbered the tent so that $t=11$ becomes $t=0, t=12$ becomes $\mathrm{t}=1$, and so on. Therefore, $\mathrm{t}=\mathrm{T}$ is $\mathrm{t}=7$. The diary of the solution is presented below:

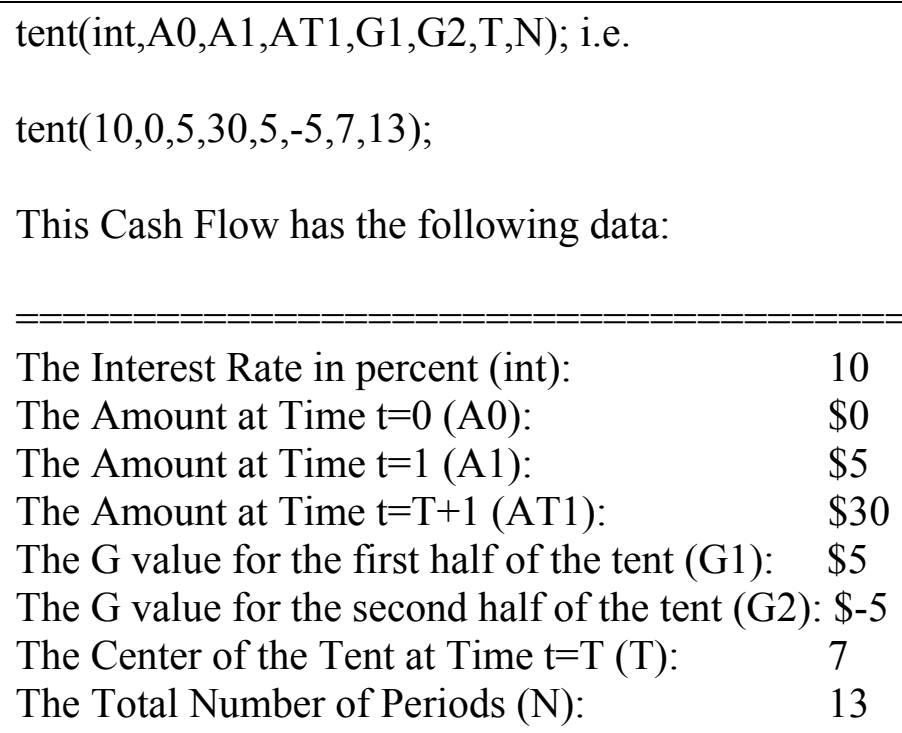

The Tent Cash Flow Analysis shows that:

The Present Value of the First Half of the Tent at time $t=11$ (renumbered $t=0$ ) is $\$ 88.1577$

The Present Value of the Second Half of the Tent at time $\mathrm{t}=\mathrm{T}=18$ (renumbered $\mathrm{t}=7$ ) is $\$ 82.237$

The Total Present Value (TPV) of the Tent at time $t=11$ (renumbered $t=0$ ) is $\$ 130.36$

The total present value for the Dual Basic Tent at time $\mathrm{t}=0$ is: $5(\mathrm{~F} / \mathrm{P}, 10 \%, 1)+\mathrm{P}_{0}+130.36(\mathrm{P} / \mathrm{F}$, $10 \%, 11)$, which in MATLAB module is given as:

$(\operatorname{fgp}(10,1) * 5)+152.23+(\operatorname{pgf}(10,11) * 130.36)=\mathbf{\$ 2 0 3 . 4 2}$

Therefore, the overall PV of this Dual Basic Tent at time $\mathrm{t}=0$ is $\mathbf{\$ 2 0 3 . 4 2}$

\section{Pedagogical Outcome Assessment}

Student comments, end-of-semester course evaluations, as well as comparative grade records indicate that the tent cash flow concept has positive impacts on student understanding. Even in psychological terms, students tend to exhibit more interest and, consequently, expend more efforts in learning the intricacies of the arithmetic gradient series cash flow. A paraphrased sample of student comments (in Engr 4223, IE 5423, University of Oklahoma; IE 518, University of Tennessee) are presented below:

"I look forward to the next interesting design of the tents."

"The interesting approach makes me more attentive to the lectures."

"I used to fear the gradient part of the course, but the instructor makes it easier to understand."

"I have failed this course twice before, but now I am expecting at least a C." 
"The instructor is enterprising and creative with the tent cash flow approach."

"Even though I hate the subject, I find the tent designs amusing and useful."

"The instructor made what appears to be a complicated topic so interestingly funny I actually enjoyed it."

"By always making the tent problem the last problem on any test, you know what is coming, so you study for it harder."

"The tent cash flows and the instructor's satirical Recipe for an F make me laugh and eager to learn. Very entertaining approach to teaching."

"The sports world case studies of gradient tent cash flows ought to be shown on ESPN"

"I wish other engineering courses could be made as fun instead of dry lectures."

From these comments, it appears that it may not necessarily be the technique itself that enhances student understanding, but the interest and the additional efforts they put into it because they find it interesting. Nonetheless, their overall engineering economy understanding appears to have improved as evidenced by the students' subsequent performance records in the Fundamentals of Engineering (FE) examination. Students often report that they feel they did very well on the engineering economy portion of the examination and that it contributed to their passing the FE examination. As a result of that success rate, Badiru was selected by the engineering student council to serve as the FE review instructor for engineering economy, which he did every year from 1989 until he moved to the University of Tennessee in 2000. He received several teaching awards, which he credits to the assessment of his engineering economy lectures. The awards include: Regents' Award for Superior Teaching (University of Oklahoma, 1995); School of Industrial Engineering Outstanding Professor of the Year Award (University of Oklahoma, 1993 and 1995); Lectureship Award, College of Engineering (University of Oklahoma, 1994 and 1995); College of Engineering Outstanding Professor of the Year (University of Oklahoma, 1993); and University of Oklahoma Associates Distinguished Lectureship Award (1988). His Ph.D. student, who taught Engr. 4223 from 1996 to 1999 also used the same instructional approaches that Badiru used. He also won a teaching award as outstanding TA.

\section{Conclusion}

There is no doubt that students learn better when they are having fun. This paper has presented a fun way of representing arithmetic gradient series cash flows to make them appear less intimidating to students. The approach uses familiar shapes of tent designs to represent arithmetic gradient series cash flows. The approach has been successfully used by the authors as instructional aids in engineering economy courses at the University of Oklahoma and the University of Tennessee. A general arithmetic gradient series cash flow equation was developed. The general equation can be used for various tent structures with the appropriate manipulations. The general tent equation is also suitable for computer programming. MATLAB modules were developed by the authors and used for illustrative examples. The general equation eliminates the problem associated with incorrect number of periods and makes geometric series analysis interesting. Further potential software implementations of the general tent cash flow equation can involve graphical animation and real-time construction and analysis of the cash flows. Other instructional aids can also be developed from the basic idea of the tent cash flow. 


\section{Bibliography}

1. Alloway, J. A. Jr., "Spreadsheets: enhancing learning and application of engineering economy techniques," Engineering Economist, No. 3, Vol. 39, pp. 263-274, 1994.

2. Badiru, Adedeji B., Class Notes for E4223: Engineering Economic Analysis, University of Oklahoma, School of Industrial Engineering, Norman, Oklahoma, 1990.

3. Greene, Jerry, "Young's Big Contract Costs Express Little," Orlando Sentinel Newspaper, Sports Page, August 10, 1984.

4. Hartman, J. C., "Engineering economy: suggestions to update a stagnant course curriculum," ASEE Annual Conference Proceedings, ASEE, p. 6, 1998.

5. Lavelle, J. P., "Reader's forum: enhancing engineering economy concepts with computer spreadsheets," Engineering Economist, No. 4, Vol. 41, pp. 381-386, 1996.

6. Lavelle, J. P., Kim L. Needy, and Heather N. Umphred, "Engineering economy - a follow-up analysis of current teaching practices," ASEE Annual Conference Proceedings, ASEE, p. 11, 1997.

7. Park, C. S., Contemporary Engineering Economics, 2/e, Addison-Wesley Publishing Company, Inc., 1997.

8. Sullivan, W. G., "Paradigm shift in engineering economy," International Industrial Engineering Conference Proceedings, IIE, pp. 333-341, 1991.

\section{Biographical Sketches of the Authors}

DR. ADEDEJI B. BADIRU is a professor and department head in the Department of Industrial Engineering at the University of Tennessee in Knoxville (abadiru@utk.edu). He was previously professor of industrial engineering and Dean of University College at the University of Oklahoma. He is a registered professional engineer and a fellow of IIE. His areas of expertise cover project management, expert systems, economic analysis, industrial development projects, quality and productivity improvement, and computer applications. He is the author of several technical papers and books. One of his publications won the Eugene L. Grant Award for Best Paper in Volume 38 of The Engineering Economist in 1994.

H. OLUFEMI OMITAOMU is a doctoral student in Industrial Engineering at the University of Tennessee (omitaomu@utk.edu). His areas of interest include engineering economy, project management, and information systems. He is a graduate teaching assistant in the fundamentals of engineering program in the college of engineering at the University of Tennessee. He holds a $\mathrm{BS}$ and MS in Mechanical Engineering. 